\title{
ATITUDE EMPREENDEDORA EM DISCENTES DE GRADUAÇÃO: ENTRE A TEORIA E A PRÁTICA
}

\author{
ENTREPRENEURIAL ATTITUDE IN UNDERGRADUATE STUDENTS: BETWEEN THEORY AND PRACTICE \\ ACTITUD EMPRENDEDORA EN DISCENTES DE GRADO: ENTRE LA TEORÍA Y LA PRÁCTICA
}

\author{
CRISTIANE KRÜGER \\ Doutoranda \\ Universidade Federal de Santa Maria - Brasil \\ cris.kruger@hotmail.com
}

ITALO FERNANDO MINELLO

Doutor

Universidade de São Paulo - Brasil

minelloif@gmail.com

Submetido em: 19/03/2017

Aprovado em: 22/06/2017

Doi: alcance.v24n2. p191-208

\section{RESUMO}

O objetivo do estudo é analisar a atitude empreendedora dos discentes de graduação do campus da Universidade Federal de Santa Maria em Frederico Westphalen. Atitude empreendedora foi definida com base na teoria do comportamento planejado, como a predisposição aprendida a atuar, ou não, de forma empreendedora. 0 comportamento foi analisado a partir do instrumento de medida da atitude empreendedora (IMAE) e se utilizou a escala Likert. A amostra é composta por 600 alunos. $O$ instrumento obteve índices confiáveis. Realizou-se análise estatística e os resultados demonstraram que a universidade empreendedora deve ser mais atuante. Discentes que cursaram disciplinas relacionadas ao empreendedorismo e aqueles que trabalham obtiveram pontuação superior em detrimento aos demais. Os resultados do presente estudo podem contribuir para novas pesquisas relacionadas à temática. $\mathrm{O}$ estudo limitou-se à amostra pesquisada. Sugere-se que estudos futuros contemplem uma amostra maior em diferentes instituições e que também considerem professores para um maior entendimento do fenômeno pesquisado.

Palavras-chave: Comportamento empreendedor. Graduação. Empreendedorismo. Indivíduo.

\section{ABSTRACT}

The aim of the study is to analyze the entrepreneurial attitude of undergraduate students from the campus of the Federal University of Santa Maria in Frederico Westphalen. Entrepreneurial attitude was defined based on the theory of planned behavior, as a learned predisposition to act, or not to act, in an entrepreneurial way. The behavior was analyzed based on the instrument of measurement of entrepreneurial attitude (IMAE), and the Likert scale was used. The sample is composed of 600 students. The instrument obtained reliable indices. Statistical analysis was performed, and the results showed that the entrepreneurial university should be more active. Students who took subjects related to entrepreneurship and those who worked scored higher than the others. The results of this study may contribute to new research related to the subject. The study was limited to the sample studied. It is suggested that future studies include a larger sample in different institutions, and also include teachers, for a better understanding of the phenomenon researched.

Keywords: Entrepreneurial behavior. Graduation. Entrepreneurship. Individual. 


\section{RESUMEN}

El objetivo del estudio es analizar la actitud emprendedora de los discentes de grado del campus de la Universidad Federal de Santa María en Frederico Westphalen. La actitud emprendedora fue definida con base en la teoría del comportamiento planeado, como la predisposición aprendida a actuar, o no, de forma emprendedora. El comportamiento se analizó a partir del instrumento de medida de la actitud emprendedora (IMAE) y se utilizó escala Likert. La muestra se compone de 600 alumnos. El instrumento obtuvo índices confiables. Se realizaron análisis estadísticos y los resultados demostraron que la universidad emprendedora debe ser más actuante. Los discentes que cursaron asignaturas relacionadas al emprendedorismo y aquellos que trabajan obtuvieron una puntuación superior, en detrimento de los demás. Los resultados del presente estudio pueden contribuir a nuevas investigaciones relacionadas con este tema. El estudio se limitó a la muestra investigada. Se sugiere que estudios futuros contemplen una muestra mayor en diferentes instituciones y que también considere profesores, para un mayor entendimiento del fenómeno investigado.

Palabras clave: Comportamiento emprendedor. Grado. Emprendedorismo. Individuo.

\section{INTRODUÇÃO}

A atitude empreendedora progride a passos largos e tem se espalhado amplamente em todo mundo nas últimas décadas. Na visão de Dolabela e Filion (2013) e Zampier e Takahashi (2014), os autores posicionam as universidades como uma das principais influenciadoras para o desenvolvimento de indivíduos empreendedores. Sob esse aspecto, as referidas instituições devem assumir um papel empreendedor diante dessa demanda, tanto em relação à gestão, ao ensino, à pesquisa e à extensão, quanto diante da interação com a comunidade, da criação de incubadoras e das empresas juniores. Dolabela e Filion (2013) ressaltam a relevância de empreendedores para a sociedade, considerando-se que atributos do comportamento empreendedor podem ser aperfeiçoados.

O ensino em cursos de graduação deve oportunizar conhecimentos que ampliem a formação superior básica e que devem estar em sintonia com as demandas da sociedade, assim como com a geração de conhecimentos na área de empreendedorismo, por meio de pesquisa científica. Outro aspecto a ser considerado no que se refere ao ensino do empreendedorismo diz respeito ao seu objetivo, que consiste tanto em repensar um negócio já existente, quanto estruturar um novo negócio, incentivando o comportamento empreendedor (KRAKAUER, 2015) e preparando o aluno para ingressar no mercado de trabalho.

Em função disso, ressalta-se a importância das universidades. Nada mais propício que as instituições de ensino e pesquisa atuarem nesta frente como fomentadoras da atitude empreendedora nos alunos, a qual incrementa o desenvolvimento econômico e social, amparadas no princípio constitucional que visa garantir a qualidade do ensino em seus diversos níveis e modalidades e é regulamentado pela Lei de Diretrizes e Bases da Educação Nacional (Lei 9.394, 1996). Por outro lado, percebe-se que existe uma lacuna entre a forma como 0 processo de aprendizagem ocorre dentro das universidades e a demanda do mercado em todos os seus segmentos. Diante disso, a premência de reflexão acerca do papel de gestores, professores, técnicos, alunos, órgãos de fomento, comunidade externa, enfim, de toda a sociedade, no intuito de contribuir para 0 comprometimento das pessoas envolvidas, de forma a estimular e desenvolver o espírito empreendedor no âmbito da universidade (CLARK, 2006).

As universidades atuam como propulsoras do desenvolvimento científico do conhecimento e estimuladoras de sua aplicação de maneira vivencial, por meio da tríade ensino, pesquisa e extensão, além da busca pelo desenvolvimento econômico e social. Esta atuação representa as diferentes dimensões para a criação e/ou a transformação de uma universidade de pesquisa em uma universidade empreendedora (ETZKOWITZ, 2013; LORENTZ, 2015). Este papel alavancador tem como prerrogativa um processo de aprendizagem aderente às demandas mencionadas anteriormente, fazendo emergir a experienciação como uma das bases para esse processo. Nesse sentido, Dolabela e Filion (2013) sugerem que esta característica singulariza o processo de aprendizagem como empreendedor ou vivencial, e a seleção de abordagens pedagógicas apropriadas promovem mudança social e desenvolvimento regional.

Diante disso, ações promotoras do empreendedorismo no âmbito das universidades agregam intensa participação dos agentes que interagem no processo, contribuindo para o desenvolvimento da mentalidade 
empreendedora em todos os níveis do ensino, da pesquisa e da extensão. Etzkowitz (2013) afirma que as universidades estão passando por uma "segunda revolução", na qual o desenvolvimento social e econômico é incorporado como parte da missão da universidade. Assim, a universidade que integra o desenvolvimento econômico e social como um a função adicional tem sido chamada "Universidade Empreendedora" (CASADO; SILUK; ZAMPIERI, 2013). Para Ferreira, Soria e Closs (2012), as universidades devem criar estruturas internas para promover e coordenar tais ações, estabelecendo estratégias para articular ensino, pesquisa e extensão com a sociedade.

Para esta desafiadora missão da universidade é que se configura um novo papel dos profissionais que nela atuam, pois conforme Audy (2006), à medida que a sociedade tem mais conhecimento, as empresas mudam suas características e o mercado de trabalho se torna mais intensivo em conhecimento, gerando demandas por um novo tipo de profissional, que se distingue por ações e atitudes empreendedoras. A partir dessa ideia, preparar as universidades para dar à sociedade as respostas às novas demandas ainda representa um grande desafio, que exige envolvimento e comprometimento da gestão, da sensibilização da comunidade acadêmica e principalmente adaptação às mudanças (CLARK, 2006).

Consta-se o crescimento da importância do indivíduo empreendedor para a sociedade, independentemente do segmento em que atua. Este trabalho investiga a realidade do empreendedorismo nas instituições de ensino superior, abordando essa questão no contexto da UFSM.

Diante deste contexto em que a sociedade anseia por indivíduos cada vez mais capazes de modificar a realidade na qual se encontram e confiando às universidades a perspectiva de geração de indivíduos cada vez mais empreendedores, como problema de pesquisa para este artigo, pretende-se saber: Quais os níveis de atitude empreendedora dos alunos de graduação da Universidade Federal de Santa Maria em Frederico Westphalen?

Isto posto, no presente estudo objetiva-se analisar a atitude empreendedora dos discentes de graduação da Universidade Federal de Santa Maria em Frederico Westphalen (UFSM-FW). Este artigo traz um apanhado dos resultados do Projeto Educação e Atitude Empreendedoras, projeto institucional da UFSM, criado pelo Grupo de Pesquisa Gestão Empreendedora e Comportamento Humano nas Organizações (GPECOM), que visa desenvolver e disseminar atitude empreendedora em discentes, docentes e gestores, buscando contribuir para a formação de uma universidade cada vez mais empreendedora.

\section{ATITUDE EMPREENDEDORA}

O valor dos empreendedores é evidente na maioria dos países em que indivíduos inovadores são altamente respeitados e muitas vezes percebidos como impulsionadores do crescimento econômico e do desenvolvimento regional (FRITSCH; WYRWICH, 2016). Os empreendedores aproveitam as oportunidades e usam a inovação e a tecnologia para conseguir avanços no mercado (TÜLÜCE; YURTKUR, 2015). Para Borasi e Finnigan (2010), o empreendedorismo converte o conhecimento em empreendimentos que fornecem valor, tanto tangível quanto intangível.

Nesse cenário a figura do empreendedor não é somente acumular conhecimentos, mas possuir atitudes, comportamentos, formas de percepção do mundo e de si mesmo, é voltar-se para atividades de risco e capacidade de inovar, de ser perseverante e de conviver com a incerteza (DOLABELA, 2008). Para Minello (2014), o comportamento do empreendedor, no papel de gestor do seu próprio negócio, evidencia-se também na sua capacidade de lidar com a adversidade e na própria adversidade. Neste caso o ensino do empreendedorismo pode ajudar a aprimorar tais características e habilidades de gestão, promovendo a aprendizagem empreendedora (LEIVA; ALEGRE; MONGE, 2014).

Para Souza (2001), desenvolver o comportamento empreendedor é capacitar o indivíduo para que ele crie, conduza e execute o processo de elaborar novos planos de vida. Nessa perspectiva, Lorentz (2015) evidencia que o indivíduo empreendedor manifesta uma série de características que o identifica, distinguindo-o de acordo com o conjunto de habilidades que mais se aproxima da sua forma de ser.

A atitude empreendedora, abordada por meio da Teoria do Comportamento Planejado (Theoryof Planned Behavior - TPB) de Ajzen (1985), é definida como uma avaliação frente a um objeto de estímulo, influenciada por crenças. De acordo com Ajzen e Fishbein (2000, p. 1), "as atitudes das pessoas seguem, espontânea e consistentemente, de crenças acessíveis na memória e então guiam o comportamento correspondente". 0 acesso às crenças varia conforme a motivação, a capacidade de classificar quanto à relevância da atitude e do contexto 
(FISHBEIN; AJZEN, 2010). Atitude prediz intenções, comportamentos que representam o esforço que a pessoa estará disposta a fazer, sendo que, quanto maior o envolvimento, melhor o desempenho (AJZEN, 1991). De acordo com Ajzen (1991), são os fatores motivacionais, representados pela intenção, e os fatores de controle comportamental, representados pala oportunidade e recursos, que determinam a concretização de um comportamento específico.

A TPB atualmente é um dos mais populares modelos sociopsicológicos para a compreensão e previsão do comportamento humano. Na TPB o antecedente imediato de um determinado comportamento é a "intenção" de realizar o comportamento em questão. Esta intenção é assumida como sendo determinada por três tipos de considerações ou crenças. O primeiro é denominado "crenças comportamentais" e refere-se às consequências positivas ou negativas da realização do comportamento e dos valores subjetivos ou das avaliações dessas consequências. Em seu agregado, as crenças comportamentais, que são facilmente acessíveis na memória, levam à formação de uma "atitude em relação ao comportamento". Um segundo tipo de consideração tem a ver com as expectativas e os comportamentos percebidos pelos indivíduos ou grupos, combinados com a motivação individual para cumprir com os referentes em questão. Essas considerações são denominadas crenças normativas. As crenças normativas, que são facilmente acessiveis na memória, se combinam para produzir uma pressão social percebida ou uma norma subjetiva em relação à realização do comportamento. $O$ terceiro tipo de consideração, as crenças de controle, está preocupado com a presença percebida de fatores que podem influenciar a capacidade de uma pessoa de realizar o comportamento. Juntamente com o poder percebido desses fatores para facilitar ou interferir no desempenho comportamental, as crenças de controle são facilmente acessíveis e produzem certo nível de controle comportamental percebido em relação ao comportamento (AJZEN, 2015).

Nesse sentido, quanto mais favorável a atitude e a norma subjetiva em relação ao envolvimento no comportamento e quanto maior o controle percebido, mais provável é que um indivíduo irá formar uma intenção de executar o comportamento em questão. Finalmente, espera-se que as intenções conduzam ao desempenho do comportamento, na medida em que as pessoas são de fato capazes de fazê-lo, isto é, na medida em que tem controle real sobre o comportamento. Sendo assim, assume-se que o poder exercido pela atitude, pela norma subjetiva e pelo controle percebido determina a intenção do comportamento (AJZEN, 2015). Na Figura 1 verificase um esquema da TPB.

Figura 1: Teoria do comportamento planejado

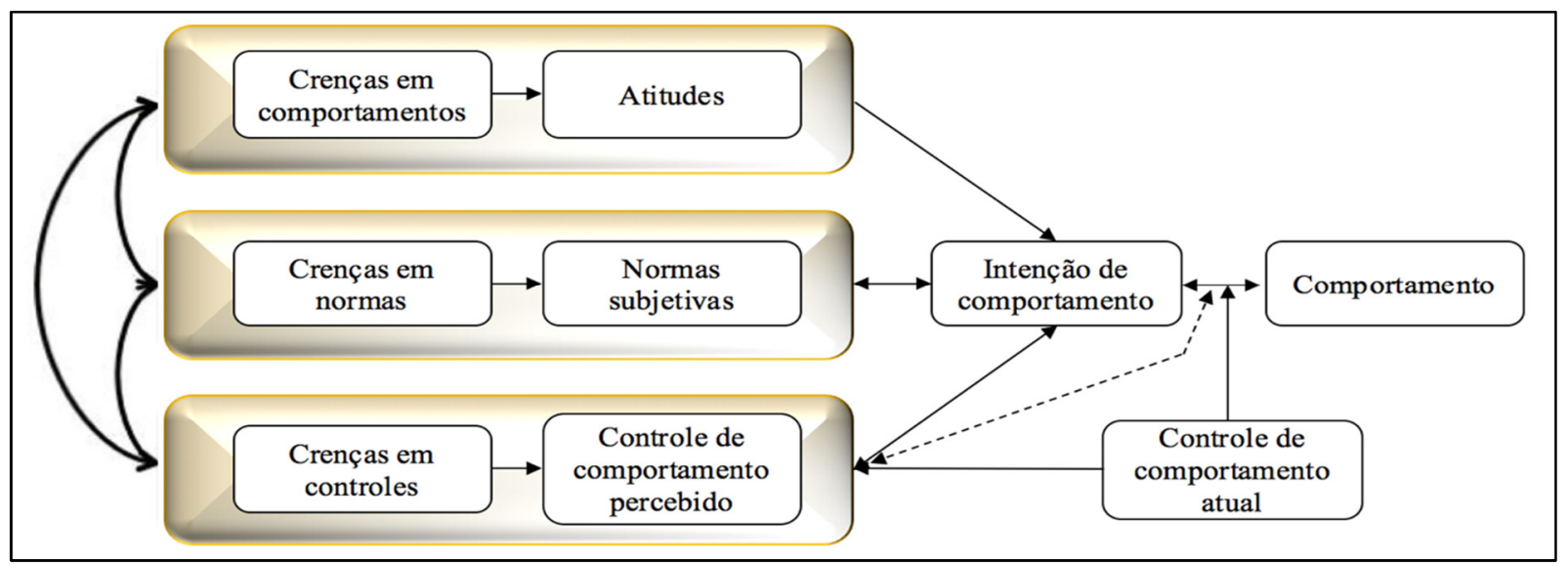

Fonte: Baseada em Ajzen (2015).

Atitude empreendedora, para Souza e Lopez Jr. (2005, p.4), é definida como a "predisposição aprendida, ou não, para agir de forma inovadora, autônoma, planejada e criativa, estabelecendo redes sociais". Pode-se entender atitude empreendedora como a intenção de agir de acordo com características comportamentais. Singer, Amorós e Arreola (2015) salientam que o conteúdo empreendedor deve ser inserido nos três níveis de educação de forma sistemática e consistente, com vistas ao desenvolvimento de uma cultura empreendedora que permeie a sociedade como um todo. Souza (2006) afirma que o comportamento empreendedor demanda de atitudes diferenciadas dos atores nela envolvidos, pois considera que o principal ativo das organizações são as pessoas.

Para atingir os diferentes objetivos do ensino de empreendedorismo, especificamente atitude 
empreendedora, elencada ao comportamento empreendedor, necessita-se traçar um plano de ensino que se adapte a metodologia pedagógica ao contexto da aprendizagem esperada (ROCHA; FREITAS, 2014). Para isso, os cursos de graduação necessitam estar em sintonia com as demandas da sociedade, assim como com a geração de conhecimentos na área de empreendedorismo, por meio de práticas didáticas que estimulem 0 desenvolvimento do comportamento empreendedor (BALCONI, 2016).

Diante do apresentado, pode-se entender atitude empreendedora como a intenção de agir de acordo com as respectivas características comportamentais.

$\mathrm{Na}$ pesquisa atual o construto de atitude empreendedora, associado à teoria do comportamento planejado, é verificado em diferentes publicações. Os autores Morales-Alonso, Pablo-Lerchundi e Vargas-Perez (2016), por exemplo, em seu estudo esclarecem a importância da exposição aos modelos de empreendedorismo sobre a intenção empreendedora dos alunos de engenharia. Os autores consideram os alunos como fundadores potenciais de novas startups de conhecimento. Com esta finalidade, os autores desenvolveram um questionário com uma amostra de 851 estudantes de engenharia de uma universidade técnica na Espanha. Os resultados apontam que os pais que possuem negócios promovem a intenção empresarial e atitudes relacionadas em seus filhos. No entanto, os funcionários públicos são identificados como um modelo de papel negativo, impedindo tanto as atitudes como as intenções para o empreendedorismo.

Madan e Popli (2016) analisaram a percepção dos educadores sobre a relação entre incentivar empreendedores, o desenvolvimento de centros de incubação, temas de empreendedorismo e educação empreendedora em instituições de ensino superior e também verificaram a associação entre as percepções dos educadores sobre a atitude empreendedora, agências de financiamento e educação empreendedora em instituições de ensino superior. $O$ estudo investigou os fatores que afetam a percepção dos educadores sobre a educação empreendedora e sugeriu estratégias para motivar os alunos a se tornarem empreendedores após completarem sua formação profissional nas instituições de ensino superior. 0 estudo é de natureza exploratória e as respostas foram obtidas de professores de várias instituições de ensino superior na região da central da Índia. A importância do estudo é que ele se concentra na identificação de vários fatores que afetam a percepção dos educadores sobre a educação empreendedora em instituições de ensino superior.

De Massis et al. (2016), com base na teoria do comportamento planejado e na literatura de atitude, desenvolveram e testaram hipóteses sobre os antecedentes situacionais e individuais da atitude empreendedora dos titulares das empresas familiares com uma amostra de 274 empresas familiares italianas. Os resultados mostraram que a atitude dos incumbentes em relação à sucessão intrafamiliar é, de fato, influenciada por antecedentes situacionais e individuais, bem como por suas interações.

Duran-Aponte e Arias-Gomez (2016) realizaram um estudo sobre atitude empreendedora e os estilos emocionais. $\mathrm{O}$ artigo apresenta resultados de um estudo na Venezuela que analisou a relação entre atitudes empresariais e estilos emocionais, observada em alunos participantes, sendo 94 alunos da Universidade Central da Venezuela com especialização em Administração de Empresas e Contabilidade e 165 alunos da Universidade Simón Bolivar com especialização em Engenharia e Administração. A pesquisa é descritiva, correlacional e não experimental. Foram utilizados dois questionários para tal análise. Os resultados indicaram que um indivíduo com uma forte atitude em relação ao empreendedorismo apresenta estilos de reflexão emocional negativos. Eles são proativos em termos de sua propensão à reflexão. Diante desses resultados, as diretrizes de treinamento devem incluir abordar os traços do futuro empreendedor e uma inclusão transversal de otimismo e atitudes proativas empreendedoras, bem como controlar e gerenciar emoções.

McNally et al. (2016) revisaram 20 anos de pesquisa e descobriram que uma medida de atitudes empreendedoras ainda não havia sido validada empiricamente, a escala Kolvereid. Os autores mostraram as diferenças de construção e de medição e as modificações pontuais de escalas existentes. McNally et al. (2016) analisaram técnicas analíticas em dados de dois grupos de estudantes universitários de dois países norteamericanos. $O$ resultado do estudo é uma miniescala de Kolvereid, considerada pelos autores como mais cautelosa e aerodinâmica. Esta escala também é um preditor eficaz para mensurar intenções empreendedoras.

Handrimurtjahjo, Setiadi e Kuncoro (2015), em seu estudo "O papel da educação empreendedora na formação de atitudes empreendedoras dos alunos", descreveram o papel da educação empreendedora, informando as atitudes empreendedoras dos alunos por meio do desenvolvimento dos centros de empreendedorismo na Indonésia e instituições de ensino superior. $O$ objetivo do estudo é identificar os fatores determinantes das atitudes e das intenções empreendedoras. Participaram do estudo 118 alunos e os dados foram coletados por meio de questionários. Os dados coletados foram analisados quanto ao seu conteúdo, apresentados 
sob a forma de gráficos e foram submetidos a um tratamento estatístico simples. Os resultados indicam que os estudantes indonésios estão cientes das competências e das qualidades fortemente ligadas ao sucesso empresarial. Os resultados do estudo contribuem para as instituições de ensino superior da Indonésia compreenderem as atitudes empreendedoras dos seus alunos e investigar o papel da educação empreendedora e normas sociais na construção de atitudes que levam a intenções empreendedoras.

No estudo de Sousa et al. (2015), intitulado de "Educação empreendedora: o papel das instituições de ensino superior sobre as atitudes empresariais dos estudantes", os autores pesquisaram uma amostra constituída por 305 alunos da Universidade dos Açores, matriculados em cursos de diferentes áreas científicas, pretendendo avaliar como, na perspectiva do estudante, a universidade pode estimular o interesse de seus alunos na criação de negócios. A partir de métodos de agrupamento hierárquico, os autores obtiveram uma tipologia de variáveis ligadas a iniciativas e atividades que poderiam ser desenvolvidas pela universidade. São apresentados também os principais resultados obtidos a partir de alguns testes de hipóteses não paramétricos e de análises de correspondência, simples e múltiplas.

O impacto da educação empreendedora nas atitudes e nas intenções empreendedoras foram estudados por Fayolle e Gailly (2015). Em seu estudo analisam se os programas de educação empreendedora realmente influenciam as atitudes e a intenção dos participantes em relação ao empreendedorismo. Os autores propõem operacionalizar o conceito de intenção empreendedora e seus antecedentes na tentativa de abordar essas questões. Os autores propõem um projeto de pesquisa original onde (1) mede-se o estado inicial e a persistência do impacto e não apenas efeitos de curto prazo; (2) lida-se com um programa obrigatório, permitindo evitar vieses de autosseleção; e (3) lida-se com um programa compacto homogêneo, em vez de programas que combinam múltiplos componentes de ensino cujos efeitos não podem ser desmembrados. Os resultados da pesquisa mostraram que os efeitos positivos de uma educação empreendedora são tanto mais acentuados quando a exposição empreendedora anterior é fraca ou inexistente. Por outro lado, para os alunos que anteriormente tinham sido significativamente expostos ao empreendedorismo, os resultados destacam contra efeitos significativos da educação empreendedora sobre os participantes.

Diante das publicações apresentadas, denota-se que o construto de atitude empreendedora é pesquisado em diferentes partes do mundo e que utiliza diferentes instrumentos e metodologias para mensuração e análise. Uma similitude identificada é que muitas vezes o construto de atitude empreendedora é associado à intenção empreendedora.

\section{METODOLOGIA}

A abordagem utilizada na presente pesquisa é quantitativa, descritiva, baseada em pesquisa teóricoempírica. Para Ramos (2013), a utilização de métodos quantitativos para análise da realidade social presente em um mesmo estudo ou separados em estudos diferentes tem o propósito de descrever e/ou comparar características de grupos sociais, realidades, contextos ou instituições e estabelecer relações causais. Richardson (2011) estabelece que a pesquisa quantitativa é uma metodologia predefinida ao respondente, reduzindo a heterogeneidade da coleta de dados, inferindo maior credibilidade aos resultados. 0 que possibilita medir as variáveis do estudo buscando averiguar sua influência sobre outras variáveis (SAMPIERI; COLLADO; LUCIO, 2013). A pesquisa descritiva procura descrever as características de uma determinada população ou os fatos e os fenômenos de uma realidade, o que pode proporcionar uma maior familiaridade com o problema, tornando-o mais explícito e favorecendo o aprimoramento de ideias e considerações dos mais variados aspectos ligados ao fato estudado (TRIVIÑOS, 1987).

Para atender o objetivo da pesquisa, utilizou-se o instrumento de medida da atitude empreendedora (IMAE) com o objetivo de mensurar a atitude empreendedora diante de quatro dimensões: realização, planejamento, poder e inovação. Com exceção da característica "inovação", as demais foram baseadas no modelo de Características Comportamentais Empreendedoras de McClelland (MSI, 1990). Nessa perspectiva, no IMAE agruparam-se as características comportamentais empreendedoras em duas dimensões: Prospecção e Inovação; e Gestão e Persistência, conforme pode ser observado na Figura 2. O IMAE é propício para mensurar a atitude empreendedora bem como investigar a capacidade de discriminar a resposta que o indivíduo está apto a dar, é composto por 36 questões e utiliza escala tipo Likert de 5 pontos, correspondendo a seguinte gradação: 1 = nunca, $2=$ raras vezes, 3 = algumas vezes, $4=$ usualmente e 5 = sempre. 
Figura 2: IMAE: Características comportamentais e dimensões

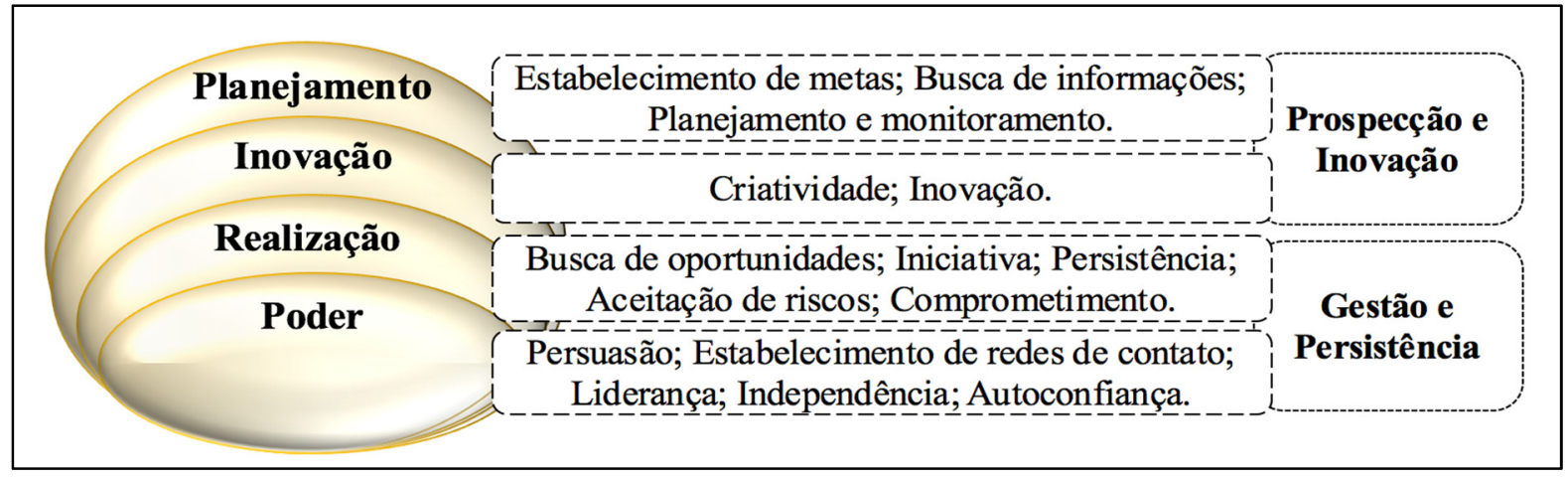

Fonte: Baseada em MSI (1990), Souza (2006) e Souza e Lopez Jr. (2005).

A população total desta pesquisa é composta por 1.028 alunos, distribuídos em 6 cursos de graduação da Universidade Federal de Santa Maria, campus Frederico Westphalen. Os cursos de graduação são: Agronomia, Engenharia Ambiental e Sanitária, Engenharia Florestal, Jornalismo, Relações Públicas e Sistemas de Informação. Calculou-se o tamanho da amostra mínima (Equação 1), que segundo Fonseca e Martins (1996), é para uma população finita. Considerou-se um nível de confiança de 95\% e um erro padrão de 5\%, a amostra mínima calculada foi de 281 alunos.

$$
n=\frac{z_{\alpha / 2}^{2} \cdot p . q \cdot N}{e^{2}(N-1)+Z_{\alpha / 2}^{2} \cdot p \cdot q}
$$

Que corresponde a:

e - erro amostral;

$\mathrm{N}$ - tamanho da população;

n - amostra mínima

$\alpha=0,05-$ Nível de Significância

$p=0,5$ e $q=0,5$

$\mathrm{Z}_{\alpha / 2}^{2}=1,96$ para um nível de confiança de $95 \%$.

A amostra é probabilística aleatória. A coleta de dados ocorreu nos meses de novembro a dezembro de 2015 e seguiu um cronograma prévio com a descrição dos horários e salas de aulas de cada turma, buscando evitar que um indivíduo responda aos instrumentos duplicadamente. Os instrumentos foram entregues pessoalmente nas salas de aula e os alunos foram convidados a participar. Participaram 615 alunos que responderam o instrumento. Foram desconsiderados 15 instrumentos preenchidos incompletamente. Os dados foram tabulados e codificados e, posteriormente, conferidos, objetivando verificar possíveis erros de digitação. Para tratamento e análise dos dados coletados, foram realizados testes estatísticos, utilizando o software "Statistical Packagefor the Social Sciences" - SPSS, versão 24. Na ocasião foram analisados quantitativamente e explorados os dados do modelo proposto por Souza e Lopez Jr. (2005).

A seguir apresenta-se a análise dos resultados que corresponde à análise de estatística descritiva, teste de normalidade Kolmogorov-Smirnov, teste de adequação da amostra de Kaiser-Meyer-Olkin (KMO), cálculo do alfa de Cronbach, análise fatorial exploratória para verificar a dimensionalidade de cada construto. Para determinar a quantidade de fatores extraídos, foi utilizado o método eigenvalue, que indica que os fatores devem ter um autovalor maior que 1 , correlação de Pearson e teste de comparação de médias, baseado nas variáveis de ter cursado disciplina de empreendedorismo (sim/não) e se trabalha (sim/não). 


\section{ANÁLISE DOS RESULTADOS}

\subsection{Característica da Amostra}

A amostra é composta por 600 discentes de graduação, sendo 295 pessoas do gênero masculino (49\%) e 305 do gênero feminino (51\%). No que se refere à faixa etária, 88\% (526) possuem até 23 anos. Em relação ao estado civil, os solteiros representam $97 \%$ dos respondentes. Quanto ao trabalho, $77 \%$ (463) dos respondentes afirmam que não trabalham. Quanto ao questionamento sobre já ter cursado disciplinas relacionadas ao empreendedorismo, $76 \%$ (457) dos respondentes afirmaram nunca ter cursado quaisquer disciplinas relacionadas ao empreendedorismo.

\subsection{Resultados e Análises}

A análise dos resultados iniciou com o cálculo das médias e desvio padrão de cada dimensão para os construtos estudados. No Quadro 1 apresentam-se a estatística descritiva e o teste de confiabilidade dos instrumentos utilizados no presente estudo.

Quadro 1: Estatística descritiva e teste de confiabilidade

\begin{tabular}{|c|c|c|c|c|c|c|c|}
\hline Dimensões & Itens & Mínimo & Máximo & Média & $\begin{array}{c}\text { Desvio } \\
\text { Padrão }\end{array}$ & Variância & $\begin{array}{c}\text { Alfa de } \\
\text { Cronbach }\end{array}$ \\
\hline Realização & 9 & 14,00 & 45,00 & 34,7383 & 4,71277 & 22,210 & 0,748 \\
\hline Planejamento & 13 & 23,00 & 65,00 & 48,7183 & 7,08067 & 50,136 & 0,836 \\
\hline Poder & 8 & 12,00 & 40,00 & 31,1350 & 4,32681 & 18,721 & 0,707 \\
\hline Inovação & 6 & 9,00 & 30,00 & 22,9767 & 3,50237 & 12,267 & 0,735 \\
\hline
\end{tabular}

$\mathrm{N}^{0}$ válido (listwise) 600.

Fonte: Elaborado pelos autores.

A partir do Quadro 1 é possível identificar as pontuações mínimas e máximas de cada característica, assim como as médias e o desvio padrão. Verifica-se que cada dimensão possui limite máximo próprio devido à quantidade de itens respectivos. O maior desvio padrão ocorre na dimensão Planejamento, que possui a maior quantidade de itens.

Para estimar a confiabilidade, foi medida a consistência interna por meio do alfa de Cronbach (SAMPIERI; COLLADO; LUCIO 2013). $O$ alfa de Cronbach é calculado pela seguinte Equação 2:

$$
\alpha=\frac{k}{k-1}\left[\frac{\sigma_{\tau}^{2}-\Sigma_{i=1 \sigma_{i}^{2}}^{k}}{\sigma_{\tau}^{2}}\right]
$$

Que corresponde a:

k corresponde ao número de itens do questionário;

$\sigma^{\wedge} 2 i$ corresponde à soma das variâncias de cada item;

$\sigma^{\wedge} 2 t$ corresponde à variância total do questionário, determinada como a soma de todas as variâncias.

Os coeficientes alfa de Cronbach das dimensões do IMAE são observáveis no Quadro 1, e o alfa de Cronbach para o instrumento IMAE obteve $\alpha=0,925$. Deste modo, os valores resultantes da aplicação dos 
questionários com os 600 discentes de graduação podem ser considerados confiáveis. no Quadro 2.

Em seguida foi realizado o teste de normalidade Kolmogorov-Smirnov, os resultados são apresentados

Quadro 2: Teste de Normalidade Kolmogorov-Smirnova

\begin{tabular}{|c|c|c|c|c|c|}
\hline Instrumento & Dimensões & Estatística & gl & Sig. & Skewness \\
\hline \multirow{3}{*}{ IMAE } & Realização &, 063 & 600 &, 000 & $-0,247$ \\
\cline { 2 - 6 } & Planejamento &, 047 & 600 &, 003 & $-0,292$ \\
\cline { 2 - 6 } & Poder &, 069 & 600 &, 000 & $-0,328$ \\
\cline { 2 - 6 } & Inovação &, 080 & 600 &, 000 & $-0,403$ \\
\hline
\end{tabular}

a Correlação de Significância de Lilliefors.

Fonte: Elaborado pelos autores.

Os resultados para o teste de normalidade indicaram que os escores das dimensões obtiveram significância menor que 0,05 , os quais indicam que a distribuição dos dados difere significativamente de uma distribuição normal (Sig.<0,05). No entanto, para Leech, Barret e Morgan (2005), pode-se considerar as variáveis aptas para testes paramétricos quando 0 Skewness constar entre $-1>\mathrm{e}<1$, quando ocorre uma normalidade aproximada, permitindo que se apliquem testes paramétricos. Neste caso, para as dimensões do IMAE, poderão realizar-se testes paramétricos.

Para verificar a adequação da amostra foi utilizada a medida de Kaiser-Meyer-Olkin (KMO). Para Hair, Black e Babin (2009), valores aceitáveis estão entre 0,5 a 1,0. Obteve-se um KMO de 0,924 para a atitude empreendedora, considerado excelente (HAIR JR; BLACK; BABIN, 2009), valor que indica que a análise fatorial é apropriada. Também foi realizado o teste de esfericidade de Bartlett com Sig. de 0,000, ou seja, rejeita-se a hipótese nula de que a matriz de correlação das variáveis é uma matriz identidade (HAIR JR.; BLACK; BABIN, 2009).

Para Almeida (2013), a análise fatorial exploratória objetiva explicar as relações de correlação entre as variáveis estudadas, identificar fatores latentes e auxiliar a mensuração e a validação de constructos complexos. Foi utilizado o método dos componentes principais, com tratamento pairwise para os casos omissos. Para determinar a quantidade de fatores extraídos, foi utilizado o método eigenvalue, que indica que os fatores devem ter um autovalor maior que 1. Quanto aos métodos de rotação, optou-se pela rotação oblíqua com o método Oblimin. O resultado da extração da análise fatorial exploratória do IMAE é apresentado no Quadro 3.

Quadro 3: Análise fatorial exploratória - IMAE

\begin{tabular}{|c|c|c|c|c|c|c|c|}
\hline \multirow{2}{*}{ Fatores } & \multicolumn{3}{|c|}{ Autovalores iniciais } & \multicolumn{3}{|c|}{$\begin{array}{c}\text { Somas de extração de } \\
\text { carregamentos ao quadrado }\end{array}$} & \multirow{2}{*}{$\begin{array}{c}\begin{array}{c}\text { Somas de } \\
\text { rotação de } \\
\text { carregamentos } \\
\text { ao quadrado }\end{array} \\
\text { Total }\end{array}$} \\
\hline & Total & $\begin{array}{c}\% \text { de } \\
\text { variância }\end{array}$ & $\begin{array}{c}\% \\
\text { cumulativa }\end{array}$ & Total & $\begin{array}{c}\% \text { de } \\
\text { variância }\end{array}$ & $\begin{array}{c}\% \\
\text { cumulativa }\end{array}$ & \\
\hline 1 & 10,196 & 28,321 & 28,321 & 10,196 & 28,321 & 28,321 & 5,706 \\
\hline 2 & 1,734 & 4,815 & 33,136 & 1,734 & 4,815 & 33,136 & 4,610 \\
\hline 3 & 1,494 & 4,151 & 37,288 & 1,494 & 4,151 & 37,288 & 4,120 \\
\hline 4 & 1,429 & 3,970 & 41,257 & 1,429 & 3,970 & 41,257 & 2,218 \\
\hline
\end{tabular}




\begin{tabular}{|c|c|c|c|c|c|c|c|}
\hline 5 & 1,273 & 3,536 & 44,794 & 1,273 & 3,536 & 44,794 & 2,319 \\
\hline 6 & 1,190 & 3,305 & 48,099 & 1,190 & 3,305 & 48,099 & 3,488 \\
\hline 7 & 1,072 & 2,977 & 51,076 & 1,072 & 2,977 & 51,076 & 4,507 \\
\hline 8 & 1,059 & 2,941 & 54,017 & 1,059 & 2,941 & 54,017 & 3,656 \\
\hline 9 & 1,012 & 2,810 & 56,827 & 1,012 & 2,810 & 56,827 & 3,561 \\
\hline 10 & 940 & 2,611 & 59,438 & & & & \\
\hline 11 & ,876 & 2,432 & 61,871 & & & & \\
\hline 12 & ,842 & 2,340 & 64,211 & & & & \\
\hline 13 & ,836 & 2,321 & 66,531 & & & & \\
\hline 14 & ,804 & 2,232 & 68,763 & & & & \\
\hline 15 & ,771 & 2,142 & 70,905 & & & & \\
\hline 16 & ,736 & 2,044 & 72,949 & & & & \\
\hline 17 & ,717 & 1,992 & 74,941 & & & & \\
\hline 18 & ,692 & 1,922 & 76,863 & & & & \\
\hline 19 & ,653 & 1,814 & 78,676 & & & & \\
\hline 20 & ,610 & 1,694 & 80,370 & & & & \\
\hline 21 &, 599 & 1,664 & 82,034 & & & & \\
\hline 22 &, 559 & 1,552 & 83,586 & & & & \\
\hline 23 &, 554 & 1,538 & 85,124 & & & & \\
\hline 24 & ,523 & 1,451 & 86,575 & & & & \\
\hline 25 & ,514 & 1,427 & 88,002 & & & & \\
\hline 26 & ,491 & 1,365 & 89,367 & & & & \\
\hline 27 & ,479 & 1,331 & 90,698 & & & & \\
\hline 28 & ,450 & 1,250 & 91,948 & & & & \\
\hline 28 & ,424 & 1,179 & 93,127 & & & & \\
\hline 29 & ,412 & 1,145 & 94,272 & & & & \\
\hline 30 & ,398 & 1,105 & 95,376 & & & & \\
\hline 31 & ,390 & 1,082 & 96,459 & & & & \\
\hline 32 & ,359 & ,996 & 97,455 & & & & \\
\hline 33 & ,338 & 940 & 98,395 & & & & \\
\hline 34 & ,326 & ,907 & 99,302 & & & & \\
\hline 35 & ,251 & ,698 & 100,000 & & & & \\
\hline 36 & 10,196 & 28,321 & 28,321 & & & & \\
\hline
\end{tabular}

Método de Extração: Análise de Componente Principal.

a Quando os componentes são correlacionados, as somas de carregamentos ao quadrado não podem ser adicionadas para se obter uma variância total.

Fonte: Elaborado pelos autores. 
A análise fatorial exploratória do IMAE forneceu 9 fatores que, conjuntamente, explicam, aproximadamente, $57 \%$ da variância, a partir do critério Kaiser, que prediz reter fatores com autovalor acima de 1 . Posteriormente foi realizada a análise gráfica do número de fatores gerados, que indicam a variância total explicada por cada fator, por meio do gráfico de escarpa (Figura 3). 0 gráfico de escarpa mostra o número de componentes fatoriais extraídos em relação aos autovalores associados a esses fatores.

Figura 3: Gráfico de escarpa da análise fatorial exploratória - IMAE

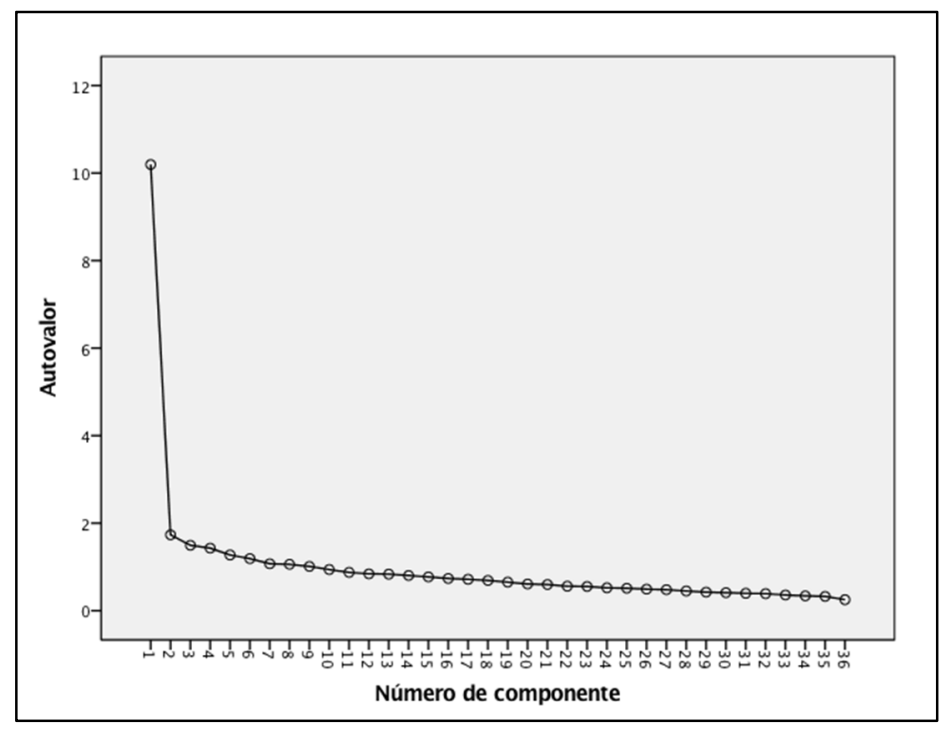

Fonte: Elaborada pelos autores.

A análise do gráfico de escarpa (Figura 3) apresentou 1 ou 2 componentes. Deste modo, as análises fatoriais dos eixos principais foram realizadas para 2 e 1 fatores, obtendo-se bons resultados em ambas soluções. (2005).

A seguir (Figura 4), apresenta-se a análise das médias da atitude empreendedora de Souza e Lopez Jr.

Figura 4: Médias da atitude empreendedora

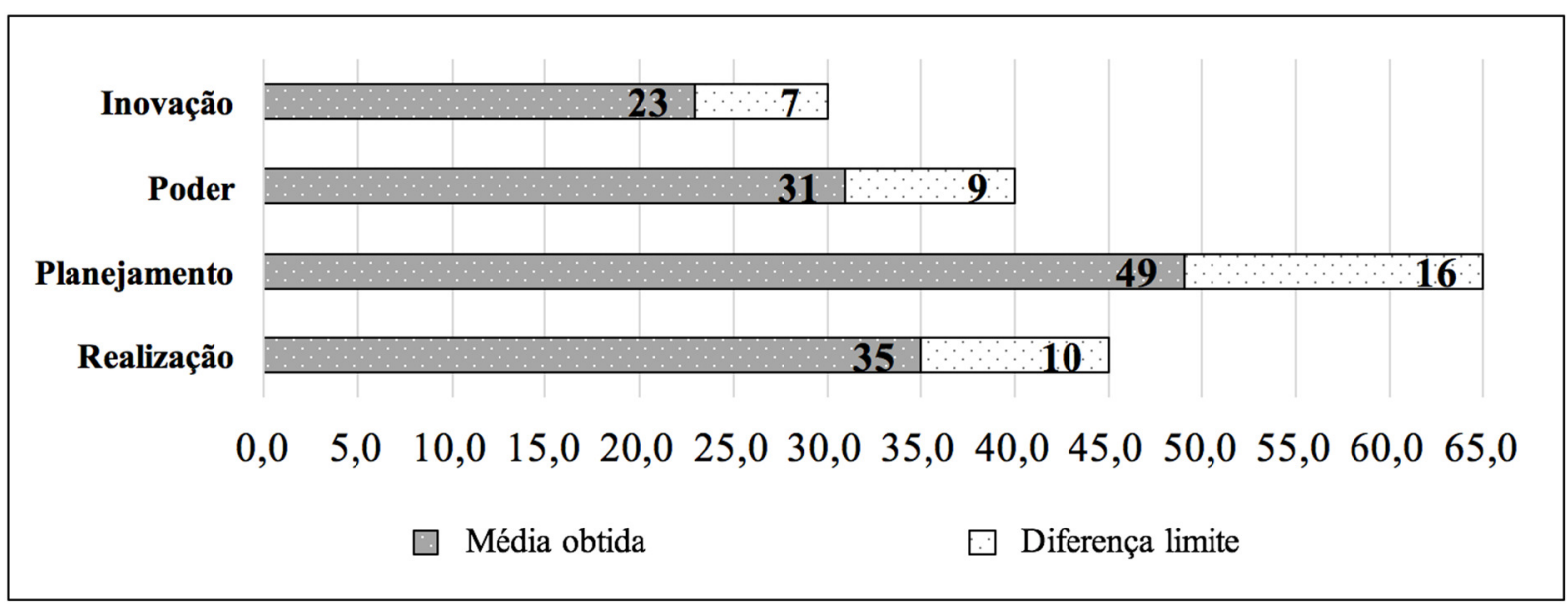

Fonte: Elaborada pelos autores.

A partir das médias (Figura 4), infere-se que os discentes possuem as dimensões de atitude empreendedora. Apesar das diferenças de limites, observa-se que a dimensão Realização possui maior pontuação dentre as quatro, muito próximo às dimensões de Inovação e Poder. A dimensão com pontuação menor dentre as 
quatro é o Planejamento, que mesmo assim ficou com uma pontuação de $75 \%$ diante do limite máximo, o que pode ser considerado uma pontuação positiva.

Com a finalidade de estabelecer relação entre as características, foi utilizado o coeficiente de correlação Pearson, que de acordo com Collis e Hussey (2005), refere-se a uma técnica paramétrica que indica a medida de força de associação entre duas variáveis. De acordo com Hair et al. (2009), o coeficiente de correlação de Pearson tem o objetivo de medir a associação linear entre duas variáveis métricas e possui variação de -1,00 a 1,00. Valores de coeficiente "r" próximos a +1 indicam pouca dispersão, o que expressa uma correlação forte e positiva; já os valores próximos de "zero" indicam muita dispersão e ausência de relação entre as variáveis; e, por fim, o valor de "r" próximo de -1 significa pouca dispersão e uma correlação negativa forte (LOPES, 2003).

Para este estudo foi adotada a conversão de Dancey e Reidy (2013), que apontam para a seguinte classificação: $r=0,10$ até 0,39 (fraco); $r=0,40$ até 0,69 (moderado); $r=0,70$ até 1,00 (forte). A matriz de correlação entre as médias da atitude empreendedora é apresentada no Quadro 4.

Quadro 4: Correlação da atitude empreendedora

\begin{tabular}{|c|c|c|c|c|}
\hline IMAE & Planejamento & Realização & Poder & Inovação \\
\hline Planejamento & 1,00 &, $755^{* *}$ &, $717^{* *}$ &, $741^{* *}$ \\
\hline Realização &, $755^{* *}$ & 1,00 &, $684^{* *}$ &, $701^{* *}$ \\
\hline Poder &, $717^{* *}$ &, $684^{* *}$ & 1,00 &, $697^{* *}$ \\
\hline Inovação &, $741^{* *}$ &, $701^{* *}$ &, $697^{* *}$ & 1,00 \\
\hline
\end{tabular}

Fonte: Elaborado pelos autores.

Verifica-se que as correlações entre as características foram associações positivas moderadas e fortes, e que indica haver relação direta entre as mesmas, sendo a correlação mais forte entre as dimensões Planejamento e Realização com 0,755 e Planejamento e Inovação com 0,741.

No Quadro 5: Comparação de médiasapresenta-se a comparação de médias diante das variáveis "ter cursado disciplina de empreendedorismo" e "se trabalha".

Quadro 5: Comparação de médias

\begin{tabular}{|c|c|c|c|c|c|c|}
\hline \multicolumn{7}{|c|}{ Variável "se cursou disciplina de empreendedorismo" } \\
\hline Opções & Frequênciaa & Realização & Planejamento & Poder & Inovação \\
\hline SIM & 132 & $22 \%$ & 35,38 & 50,03 & 31,62 & 23,41 \\
\hline NAO & 456 & $76 \%$ & 34,53 & 48,34 & 30,98 & 22,85 \\
\hline \multicolumn{7}{|c|}{ Variável "se trabalha" } \\
\hline Opções & Frequênciaa & Realização & Planejamento & Poder & Inovação \\
\hline SIM & 126 & $21 \%$ & 35,41 & 50,20 & 31,62 & 23,45 \\
\hline NAO & 462 & $77 \%$ & 34,54 & 48,32 & 30,99 & 22,86 \\
\hline
\end{tabular}

a $2 \%$ não respondeu.

Fonte: Elaborado pelos autores.

A partir do Quadro 5, observa-se que todas dimensões da atitude empreendedora obtiveram pontuação superior para aqueles alunos que cursaram alguma disciplina relacionada ao empreendedorismo; e para aqueles alunos que trabalham, esses resultados evidenciam a importância da prática. Para Dolabela (2008), aprende-se a ser empreendedor pela convivência com outros empreendedores, o comportamento empreendedor pode ser 
aprendido por meio da experiência de terceiros. Para Dolabela e Filion (2013), o ensino do empreendedorismo não deve restringir-se apenas ao âmbito acadêmico, este deve ser inserido com pequenos conceitos e práticas a partir da educação infantil, estimulando desde cedo aspectos empreendedores nos alunos, o que reforça a importância da prática do comportamento empreendedor desde cedo.

\section{CONSIDERAÇÕES FINAIS}

O estudo visou analisar a atitude empreendedora dos discentes de graduação do campus da Universidade Federal de Santa Maria em Frederico Westphalen, evidenciando que os alunos possuem as quatro dimensões de atitude empreendedora. No entanto, dos alunos pesquisados, apenas $22 \%$ afirmaram terem cursado alguma disciplina relacionada à temática empreendedorismo, o que vem na contramão do princípio da universidade empreendedora, que para Clark (2006), fundamenta-se numa cultura empreendedora permeando por toda universidade. Verifica-se que a universidade empreendedora ainda não está concretizada na instituição estudada e não se pode afirmar que a pontuação obtida na atitude empreendedora esteja diretamente relacionada a ações da universidade empreendedora, pois poucos alunos revelaram terem participado de disciplinas ou atividades relacionadas ao tema pesquisado.

A análise fatorial exploratória forneceu 9 fatores que, conjuntamente, explicam $57 \%$ da variância. Pela análise do gráfico de escarpa, verificou-se 1 ou 2 componentes para o construto. Deste modo, a análise fatorial dos eixos foi realizada para 2 e 1 fatores. Obtiveram-se resultados satisfatórios nas análises. Quanto às associações por meio da correlação de Pearson, foram positivas moderadas e fortes, o que indica haver relação direta entre as mesmas, e a correlação mais forte ocorreu entre as dimensões Planejamento e Realização $(0,755)$ e Planejamento e Inovação $(0,741)$.

Nesse sentido, os resultados do estudo revelam que a universidade empreendedora deve ser mais atuante, visto que os alunos que já vivenciaram atividades relacionadas à temática do empreendedorismo, apesar de baixo percentual de participantes, obtiveram pontuação superior diante dos alunos que não tiveram tal experiência. Da mesma forma, os alunos que trabalham obtiveram pontuação superior em relação aos alunos que não o fazem, o que denota a importância tanto da teoria quanto da prática no contexto da universidade empreendedora, em que o comportamento empreendedor e, por sua vez a atitude empreendedora, pode ser construído por meio destes.

Esses achados podem contribuir para novas pesquisas relacionadas ao empreendedorismo, à educação empreendedora, à universidade empreendedora e à atitude empreendedora, dentre outras. Diante do paradoxo teoria e prática quanto ao comportamento empreendedor dos discentes, evidenciou-se que tanto a vivência por meio de disciplinas e atividades empreendedoras quanto a atividade profissional podem proporcionar autoconhecimento e autodesenvolvimento.

A presente pesquisa contou com algumas limitações relacionadas à amostra. Uma amostra maior, que contemple mais cursos ou instituições de ensino superior em diversas regiões do país e fora, com um maior percentual de estudantes que já tenham cursado alguma disciplina relacionada ao empreendedorismo ou que trabalhem, pode proporcionar uma maior variância dos dados e uma maior compreensão do fenômeno estudado. Outra limitação refere-se ao instrumento utilizado. Existem outras variáveis que podem contribuir para a composição do comportamento empreendedor, assim como para a atitude empreendedora. No entanto, o estudo restringiu-se ao instrumento escolhido.

Para estudos posteriores, recomenda-se replicar a presente pesquisa em outros cursos de graduação da instituição, evidenciando similaridades e discrepâncias dentre os cursos de ensino superior. Também se sugere a replicação da presente pesquisa em outras instituições de ensino superior do Brasil e fora, de modo a comparar resultados de instituições públicas e privadas, e até mesmo com os professores, visto que os professores não devem simplesmente ser fontes de conhecimento, mas sim desenvolver ações empreendedoras para a construção de um sistema educacional melhor, influenciando seus papéis e conduta geral (NETO; ROGRIDUES; PANZE, 2017).

\section{REFERÊNCIAS}

AJZEN, I. Consumer attitudes and behavior. In: C. P. Haugtvedt, P. M. Herr \& F. R. Cardes (Eds.). Handbook of Consumer Psychology. p. 525- 548, New York: Lawrence Erlbaum Associates, 2008.

Revista Alcance - Eletrônica - vol. 24 - n. 2 - abr.jjun. 2017 
AJZEN, I. Consumer attitudes and behavior: the theory of planned behavior applied to food consumption decisions. Rivista di Economia Agraria, Anno LXX, n. 2, 2015.

AJZEN, I. From intentions to actions: A theory of planned behavior. In: J. Kuhl \& J. Beckman (Eds.). Action-control: From cognition to behavior. p. 11-39. Heidelberg: Springer, 1985.

AJZEN, I. The theory of planned behavior. Organizational Behavior and Human Decision Processes, v. 50, p. 179-211, 1991.

AJZEN, I; FISHBEIN, M. Attitudes and Attitude-Behavior Relation: reasoned and automatic processes. In: STROBE, W.; HEWSTONE, M. (Ed.). European Review of Social Psychology, p. 1- 33, John Wiley and Sons, 2000.

AUDY, J.; FERREIRA. G. C. Universidade empreendedora: uma visão da PUCRS. In: AUDY, J. L. N.; MOROSINI, M. C. (Org.). Inovação e Empreendedorismo na Universidade. Porto Alegre: EDIPUCRS, 2006.

BALCONI, S. B. A influência das atividades de educação empreendedora sobre as características empreendedoras dos alunos de graduação da UFSM. Dissertação (Mestrado em Gestão de Organizações Públicas). UFSM, Santa Maria, 2016.

BORASI, R.; FINNIGAN, K. Entrepreneurial attitudes and behaviors that can help prepare successful changeagents in education. The New Educator, 2010.

CASADO, F. L.; SILUK, J. C. M.; ZAMPIERI, N. L. V. Universidade empreendedora e desenvolvimento regional sustentável: proposta de um modelo. Rev. Adm. UFSM, Santa Maria, v. 5, Edição Especial, p. 633-650, Dez, 2013.

CLARK, B. Pursuing the entrepreneurial University. In: AUDY, J. L. N.; MOROSINI, M. C. (Org.). Inovação e Empreendedorismo na Universidade. Porto Alegre: EDIPUCRS, 2006.

COLLIS, J.; HUSSEY, R. Pesquisa em administração: um guia prático para alunos de graduação e pósgraduação. Bookman, 2005.

DANCEY, C. P.; REIDY, J. Estatística Sem Matemática para Psicologia: Usando SPSS para Windows. 5. ed. Porto Alegre: Penso, 2013.

DE MASSIS, A.; SIEGER, P.; CHUA, J. H.; VISMARA, S. Incumbents' Attitude Toward Intrafamily Succession: An Investigation of Its Antecedents. Family business review. V. 29, n. 3, 2016.

DOLABELA, F. Oficina do empreendedor. Rio de Janeiro: Sextante, 2008.

DOLABELA, F.; FILION, L. J. Fazendo revolução no Brasil: a introdução da pedagogia empreendedora nos estágios iniciais da educação. Revista de Empreendedorismo e Gestão de Pequenas Empresas, v. 3, n. 2, 2013.

DURAN-APONTE, E.; ARIAS-GOMEZ, D. Entrepreneurial attitude and emotional styles. Contributions to the design of the training of future entrepreneurs. Revista gestion de la educacion. V. 6, n. 2, 2016.

ETZKOWITZ, H. Hélice Tríplice - Universidade-Indústria-Governo, Inovação em movimento. Porto Alegre: PUCRS, 2009.

FAYOLLE, A.; GAILLY, B. The Impact of Entrepreneurship Education on Entrepreneurial Attitudes and Intention: Hysteresis and Persistence. Journal of small business management, V. 53, 1, 2015.

FERREIRA, G. C.; SORIA, A. F.; CLOSS, L. Gestão da interação Universidade - Empresa: o caso PUCRS. Revista Sociedade e Estado - v. 27 n.1, Janeiro/Abril 2012.

FIALA, N. As incubadoras como instrumento effectual de aprendizagem do empreendedorismo. Dissertação (Mestrado em Administração) - Faculdade Getúlio Vargas, 2012.

FISHBEIN, M.; AJZEN, I. Predicting and changing behavior: The reasoned action approach New York: Psychology Press, 2010.

FONSECA, J. S, MARTINS, G. Curso de Estatística. São Paulo: Atlas,1996.

FRITSCH, M.; WYRWICH, M. The effect of entrepreneurship on economic developmentdan empirical analysis using regional entrepreneurship culture. Journal of Economic Geography, 2016.

HAIR, J. F. JR.; BLACK, W. C.; BABIN, B.; ANDERSON, R. E.; TATHAM, R. L. Análise multivariada de dados. 
2009. 6a ed., A. Sant'Anna, Trad. Porto Alegre: Bookman. Obra original publicada em 2006.

HANDRIMURTJAHJO, A. D.; SETIADI, N. J.; KUNCORO, E. The Role of Entrepreneurship Education in Forming Students' Entrepreneurial Attitudes. Advanced science letters. v. 21, n. 4, 2015.

KRAKAUER, P. V. C. Ensino de empreendedorismo: utilização do business model generation. RAI. v. 12.1 p. 723, 2015.

LEECH, N. L.; BARRET, K. C.; MORGAN, G. A. SPSS for intermediate statistics: use and interpretation. 2005.

LEIVA, J. C.; ALEGRE, J.; MONGE, R. The influence of Entrepreneurial learning in new Firms' performance: a study in Costa Rica. Rev. Inovar, v. 24, edición especial, 2014.

LOPES, L. F. D. Estatística geral. Caderno didático. Santa Maria: UFSM, 2003.

LORENTZ, M. H. N. O Comportamento Empreendedor de Diretores da UFSM e sua percepção quanto à Universidade Empreendedora. Dissertação apresentada ao Curso de Mestrado Profissional em Gestão de Organizações Públicas do Programa de Pós-Graduação em Administração, 2015.

MADAN, M.; POPLI, A. Perception of educators on entrepreneurship education: an empirical study. Jims8m-the journal of indian management \& strategy. v. 21, n, 3, 2016.

MANAGEMENT SYSTEMS INTERNATIONAL (MSI). Final Report: entrepreneurship training and the strengthening of entrepreneurial performance. 1990.

MANSFIELD, R. S.; MCCLELLAND, D. C.; SPENCER, J. L. M.; SANTIAGO, J. The identification and assessment of competencies and other personal characteristics of entrepreneurs in developing countries. Final report. McBer and Compay. Massachusetts, 1987.

MCCLELLAND, D. C. A sociedade competitiva: realização e progresso social. Rio de Janeiro: Expressão e Cultura. 1972.

MCNALLY, J. J.; MARTIN, B. C.; HONIG, B; BERGMANN, B.; PIPEROPOULOS, P. Toward rigor and parsimony: a primary validation of Kolvereid's (1996) entrepreneurial attitudes scales. Entrepreneurship and regional development. v. 28, n. 5, 2016.

MINELLO, I. F. Resiliência e Insucesso Empresarial: o comportamento do empreendedor diante do fracasso nos negócios. Curitiba: Appris, 2014.

MORALES-ALONSO, G.; PABLO-LERCHUNDI, I.; VARGAS-PEREZ, A. M. An Empirical Study on the Antecedents of Knowledge Intensive Entrepreneurship. International journal of innovation and technology management. $v$. 13, n. 5, 2016.

NETO, R. C. A.; RODRIGUES, V. P.; PANZE, S. Exploring the relationship between entrepreneurial behavior and teachers' job satisfaction. Teaching and Teacher Education, 63, 2017.

RAMOS, M. P. Métodos Quantitativos e Pesquisa em Ciências Sociais: Lógica e Utilidade do Uso da Quantificação nas Explicações dos Fenômenos Sociais. Mediações - Revista de Ciências Sociais, v. 18, n. 1, p. 55-65, 2013.

RICHARDSON, R. J.; Pesquisa Social: Métodos e Técnicas. São Paulo: Atlas, 2011.

ROCHA, E.L. C.; FREITAS, A. A. F. Avaliação do Ensino de Empreendedorismo entre Estudantes Universitários por meio do Perfil Empreendedor. Revista de Administração contemporânea. RAC, Rio de Janeiro, v. 18, n. 4, art. 5, pp. 465-486, Jul. /Ago, 2014.

SAMPIERI, R.H.; COLLADO, C.F.; LUCIO, P.B. Metodologia da Pesquisa. São Paulo: McGraw-Hill, 2013.

SINGER, S.; AMORÓS, J. E.; ARREOLA, D. M. Global Entrepreneurship Monitor - 2014. Disponível em: <Global Report. http://www.gemconsortium.org/docs/ download/3616>. Acesso em: 10 mar. 2016.

SOUSA, A.; COUTO, G.; BRANCO, N.; SILVA, O.; BACELAR-NICOLAU, H. Entrepreneurship education: the role of the higher education institutions on the entrepreneurial attitudes of the students. Iceri2015: 8th international conference of education, research and innovation, 2015.

SOUZA, E. C. L. Empreendedorismo: da gênese à contemporaneidade. In: SOUZA, Eda C. Lucas; GUIMARÃES, Tomás de Aquino. (Org.). Empreendedorismo além do plano de negócio. 1. ed. São Paulo: Atlas, 2006. 
SOUZA, E. C. L; LOPEZ JR., G. S. Atitude empreendedora em proprietários-gerentes de pequenas empresas: construção de um instrumento de medida. Revista Eletrônica de Administração, v. 11, n. 6, p. 1-21, nov./dez, 2005.

TRIVIÑOS, A. N. S. Introdução à pesquisa em ciências sociais: a pesquisa qualitativa em educação. 1. ed. São Paulo: Atlas, 1987.

TÜLÜCE, N. S.; YURTKUR, A. K. Term of strategic entrepreneurship and Schumpeter's creative destruction theory. Procedia-Social and Behavioral Sciences, 2015.

ZAMPIER, M. A.; TAKAHASHI, A. R. W. Competências e aprendizagem empreendedora em MPE's educacionais. Revista Pensamento Contemporâneo em Administração. v. 8, n. 3, 2014. 
ANEXO A - IMAE (SOUZA, LOPEZ JR., 2005)

Responda atentamente cada afirmação e marque a alternativa que descreva você da melhor forma (considere com você é hoje, e não como gostaria de ser).

\begin{tabular}{|c|c|c|c|c|c|}
\hline $\begin{array}{l}\text { Questionário de Atitude Empreendedora (IMAE) de Souza e Lopez } \\
\text { Jr. (2005) }\end{array}$ & 旁 & 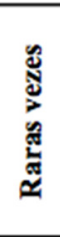 & 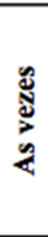 & 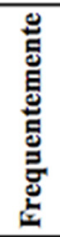 & 莒 \\
\hline $\begin{array}{l}\text { 1. Implemento novas ideias com o objetivo de melhorar a qualidade do } \\
\text { meu trabalho/atividade. }\end{array}$ & 1 & 2 & 3 & 4 & 5 \\
\hline 2. Exploro novas oportunidades. & 1 & 2 & 3 & 4 & 5 \\
\hline 3. Mudo de estratégia, se necessário, para alcançar uma meta. & 1 & 2 & 3 & 4 & 5 \\
\hline 4. Assumo riscos para expandir meu trabalho/atividade. & 1 & 2 & 3 & 4 & 5 \\
\hline 5. Defino metas de longo prazo, claras e específicas. & 1 & 2 & 3 & 4 & 5 \\
\hline $\begin{array}{l}\text { 6. .Adoto procedimentos para assegurar que o trabalho atenda padrões e } \\
\text { qualidade previamente estipulados. }\end{array}$ & 1 & 2 & 3 & 4 & 5 \\
\hline 7. Utilizo contatos pessoais para atingir meus objetivos. & 1 & 2 & 3 & 4 & 5 \\
\hline $\begin{array}{l}\text { 8. Responsabilizo-me pela conclusão dos trabalhos nos prazos } \\
\text { estipulados. }\end{array}$ & 1 & 2 & 3 & 4 & 5 \\
\hline 9. Busco obter informações sobre possíveis oportunidades. & 1 & 2 & 3 & 4 & 5 \\
\hline 10. Confio na minha capacidade de superar desafios. & 1 & 2 & 3 & 4 & 5 \\
\hline 11. Busco novas maneiras de realizar tarefas. & 1 & 2 & 3 & 4 & 5 \\
\hline 12. Faço projeções claras para o futuro do meu trabalho/atividade. & 1 & 2 & 3 & 4 & 5 \\
\hline 13. Junto-me aos colegas/pares nas tarefas para cumprir os prazos.. & 1 & 2 & 3 & 4 & 5 \\
\hline 14. Utilizo estratégias deliberadas para influenciar pessoas. & 1 & 2 & 3 & 4 & 5 \\
\hline 15. Reviso continuamente objetivos de curto prazo. & 1 & 2 & 3 & 4 & 5 \\
\hline 16. Busco informações sobre minha área em diferentes fontes. & 1 & 2 & 3 & 4 & 5 \\
\hline 17. Faço sacrifícios pessoais para concluir tarefas. & 1 & 2 & 3 & 4 & 5 \\
\hline $\begin{array}{l}\text { 18. Mantenho meus objetivos mesmo diante de resultados que não são } \\
\text { satisfatórios inicialmente. }\end{array}$ & 1 & 2 & 3 & 4 & 5 \\
\hline 19. Consulto meus registros de controle antes de tomar decisões. & 1 & 2 & 3 & 4 & 5 \\
\hline 20. Renovo meus esforços para superar obstáculos. & 1 & 2 & 3 & 4 & 5 \\
\hline $\begin{array}{l}\text { 21. Busco novas soluções para atender necessidade de } \\
\text { colegas/pares/alunos. }\end{array}$ & 1 & 2 & 3 & 4 & 5 \\
\hline $\begin{array}{l}\text { 22. Planejo as atividades do meu trabalho subdividindo tarefas de } \\
\text { grande porte em subtarefas. }\end{array}$ & 1 & 2 & 3 & 4 & 5 \\
\hline 23. Procuro criar novas ideias. & 1 & 2 & 3 & 4 & 5 \\
\hline $\begin{array}{l}\text { 24. Assumo a responsabilidade pela resolução de problemas que possam } \\
\text { prejudicar o desempenho do meu trabalho/atividade. }\end{array}$ & 1 & 2 & 3 & 4 & 5 \\
\hline $\begin{array}{l}\text { 25. Considero-me principal responsável pelo meu desempenho no meu } \\
\text { trabalho/atividade. }\end{array}$ & 1 & 2 & 3 & 4 & 5 \\
\hline
\end{tabular}




\begin{tabular}{|l|l|l|l|l|l|}
\hline $\begin{array}{l}\text { 26. Confio na minha competência como fonte do sucesso do meu } \\
\text { trabalho/atividade. }\end{array}$ & 1 & 2 & 3 & 4 & 5 \\
\hline 27. Emprego esforços extras para a conclusão de tarefas programadas. & 1 & 2 & 3 & 4 & 5 \\
\hline 28. Desenvolvo ideias novas para a solução de problemas. & 1 & 2 & 3 & 4 & 5 \\
\hline 29. Defino continuamente objetivos de curto prazo. & 1 & 2 & 3 & 4 & 5 \\
\hline 30. Assumo riscos com o intuito de superar problemas. & 1 & 2 & 3 & 4 & 5 \\
\hline $\begin{array}{l}\text { 31. Crio novas rotinas, objetivando a melhoria do desempenho do meu } \\
\text { trabalho/atividade. }\end{array}$ & 1 & 2 & 3 & 4 & 5 \\
\hline 32. Ajo antes de ser pressionado pelas circunstancias. & 1 & 2 & 3 & 4 & 5 \\
\hline 33. Costumo calcular o risco envolvido nos negócios que faço. & 1 & 2 & 3 & 4 & 5 \\
\hline 34. Calculo os riscos antes de novos investimentos. & 1 & 2 & 3 & 4 & 5 \\
\hline 35. Estimulo o espírito de equipe entre meus colegas/pares/alunos. & 1 & 2 & 3 & 4 & 5 \\
\hline $\begin{array}{l}\text { 36. Estimulo a participação dos meus colegas/pares/alunos na busca } \\
\text { pela solução de um problema. }\end{array}$ & 1 & 2 & 3 & 4 & 5 \\
\hline
\end{tabular}

